\title{
Optimizing the Duration of Acclimatization under Artificial Light for St. John's Wort Plantlets Grown Photoautotrophically and Photomixotrophically In Vitro
}

\author{
Marcio Akira Couceiro, Sayed M. A. Zobayed, Fawzia Afreen, \\ Eiji GoTO and Toyoki KozAI \\ Laboratory of Environmental Control Engineering, Department of Bioproduction Science, \\ Faculty of Horticulture, Chiba University, \\ Matsudo, Chiba 271-8510, Japan
}

(Received October 12, 2005)

\begin{abstract}
For production of high-quality St. John's wort (Hypericum perforatum L.) transplants, several authors have proposed in vitro multiplication of a superior germplasm by clonal propagation followed by ex vitro acclimatization in the greenhouse with natural light. This ex vitro acclimatization is a vital stage for successful transplant production. However, few studies have attempted to determine the optimum conditions for ex vitro acclimatization under artificial light. The objective of the current study was to find the necessary duration of ex vitro acclimatization by gradually reducing relative humidity under controlled environments with artificial light for St. John's wort plantlets grown photomixotrophically (sugar-containing medium) and photoautotrophically (sugar-free medium) in vitro. The results showed that all photoautotrophically- and photomixotrophically-grown plantlets survived after the ex vitro acclimatization. Plantlets grown photoautotrophically in vitro were most suitable acclimatized to ex vitro environments by decreasing the relative humidity from 90 to $65 \%$ within two days. Meanwhile, the results suggested that plantlets grown photomixotrophically in vitro were most suitable acclimatized to ex vitro environments within four or seven days.
\end{abstract}

Keywords : Hypericum perforatum L., medicinal plants, photoautotrophic, photomixotrophic, relative humidity

\section{INTRODUCTION}

Recently the annual market value of plant-based medicine has exceeded $\$ 15$ billion worldwide, and the annual market of St. John's wort (Hypericum perforatum L.) has exceeded $\$ 570$ million (Grunwald, 1999; Kamboj, 2000; Zobayed et al., 2005). St. John's wort is a medicinal plant native to Europe and North Africa (Deltito and Beyer, 1998) with a long history for treatments of neurological disorders and depression, and recently has shown a potential as a novel anticancer drug (Schempp et al., 2002). More than 25 potentially bioactive compounds have been found in St. John's wort tissues (Miller, 1998), although the quality of this plant is mainly based on the amounts of hypericin, pseudohypericin and hyperforin (Orth et al., 1999).

The hypericin and pseudohypericin contents in commercially prepared St. John's wort capsules were found to vary by factors of 17 and 13, respectively, (Consumer Safety Symposium on

Corresponding author: Marco Akira Couceiro, fax : +81-47-308-8843

e-mail : marcio@graduate.chiba-u.jp 
Dietary Supplements and Herbs, 1998). This variation in contents of medicinal plant products is considered as one of the critical ongoing problems with plant-based medicines (Zobayed and Saxena, 2004). Possible reasons for the wide variation are the effect of changeable environments on the synthesis of medicinal compounds, the genetic variability, and lack of standard methods for plant production (Murch et al., 2000; Zobayed and Saxena, 2004). Moreover, plants grown under greenhouse with natural light or field conditions have normally been used for phytopharmaceutical preparations and are therefore commonly infected by pollutants, pathogens, and insects that can alter the contents of bioactive compounds in plant tissues. Recently, advances in the area of environmental control engineering have offered some solutions to these problems, enabling the mass production of consistent and standardized medicinal plant materials (Zobayed et al., 2005). One production method is in vitro propagation of superior germplasm-plant with high biomass and bioactive compound production. These superior plants are transferred to growth chambers under artificial light, and all other ex vitro environment conditions are optimized throughout the acclimatization and growing period (Zobayed and Saxena, 2004; Mosaleeyanon et al., 2005; Couceiro et al., 2006b).

The concept of growing plants ex vitro in growth chambers under controlled environments with artificial light was first proposed by Kozai et al. (1999) as an appropriate production system for high-quality transplants with minimum use of energy, material and human resources. Recently, Zobayed et al. (2005) proposed a similar system for production of medicinal plants. Under controlled environments with artificial light, physical factors such as photosynthetic photon flux, $\mathrm{CO}_{2}$ concentration and relative humidity can be easily controlled, regardless the outside weather. This technology has several advantages for production of medicinal plants. It makes possible to (1) control production and the time of delivery, (2) grow plants independent of environmental, seasonal, and geographical limitations, (3) control and optimize the air temperature, relative humidity, $\mathrm{CO}_{2}$ concentration and air current speed regardless the outer environment, (4) maximize growth and medicinal concentrations, (5) shorten the production period, and (6) prevent damage from insects, pest and pathogenic microorganisms (Couceiro et al., 2006b; Zobayed et al., 2005).

In our previous study, we have obtained a greater in vitro growth of St. John's wort plantlets under photoautotrophic conditions (sugar-free medium) than under photomixotrophic (sugarcontaining medium) conditions (Couceiro et al., 2006a). In addition, Zobayed and Saxena (2004) increased the biomass and bioactive compounds of St. John's wort by controlling the ex vitro environment under artificial light. The stage of acclimatization of in vitro-grown plants to the ex vitro environment is usually the most vulnerable period (Preece and Sutter, 1991; Kozai et al., 2005). However, so far no study has been conducted on this stage for St. John's wort plants under controlled environments with artificial light.

In several recent studies, St. John's wort plants in greenhouses under natural light have been acclimatized by gradually exposing them to ambient humidity from high relative humidity (over to $90 \%$, in vitro conditions) within seven to 14 days (Murch et al., 2000; Pretto and Santarem, 2000; Zobayed et al., 2004; Zobayed and Saxena, 2004). However, one of the advantages of controlling the ex vitro environment under artificial light is the reduction of the acclimatization and culture period ex vitro, as well as the high survival rate after transplanting (Kozai et al., 2005). For that reason, the objective of this study was to find the optimum duration of acclimatization by reducing the relative humidity under controlled environments with artificial light for St. John's wort plantlets grown photomixotrophically (Pm, sugar-containing medium) and photoautotrophically (Pa, sugarfree medium) in vitro, that ensure high growth and chlorophyll concentration after transplanting to ex vitro environments. 


\section{MATERIALS AND METHODS}

\section{Plant materials}

Twenty-one-day-old St. John's wort (Hypericum perforatum L.) plantlets grown in vitro under: (a) photomixotrophic (sugar-containing medium) conditions, and (b) under photoautotrophic (sugar-free medium) conditions were used as plant materials. Photomixotrophically grown plantlets, hereafter referred as Pm, were regenerated from nodal cuttings $(1 \mathrm{~cm}$ long) with a pair of unfolded leaves in Magenta-type vessels $(370 \mathrm{ml}$ in volume) containing half-strength MS (Murashige and Skoog, 1962) solution, $30 \mathrm{~g} \mathrm{l}^{-1}$ sucrose and vitamins, with low number of air exchanges $\left(0.3 \mathrm{~h}^{-1}\right.$; estimated according to Kozai et al., 1986). The vessels were covered with polypropylene lids and sealed with Parafilm (American National Can ${ }^{\mathrm{TM}}$, Chicago, IL). Under photomixotrophic conditions, agar (Kanto Chemical Co., Inc, Tokyo, Japan) was used as supporting material $\left(8 \mathrm{~g} \mathrm{l}^{-1}\right)$, and each vessel contained $50 \mathrm{ml}$ of the medium. The $\mathrm{pH}$ of the medium was adjusted to 5.7 before autoclaving at $121 \mathrm{C}$ for $20 \mathrm{~min}$. Photosynthetic photon flux (PPF) was 70 $\mu \mathrm{mol} \mathrm{m} \mathrm{m}^{-2} \mathrm{~s}^{-1}$ provided by cool-white fluorescent tubes (National Co., Tokyo, Japan), measured on an empty shelf surface. Photoperiod was $16 \mathrm{~h} \mathrm{~d}^{-1}$, air current speed around the vessels was approximately $0.25 \mathrm{~m} \mathrm{~s}^{-1}$, relative humidity was $65 \pm 5 \%$ and the $\mathrm{CO}_{2}$ concentration was $400 \pm 50 \mu \mathrm{mol}$ $\mathrm{mol}^{-1}$. The photoautotrophically grown plantlets, hereafter referred as $\mathrm{Pa}$, were regenerated from nodal cuttings ( $1 \mathrm{~cm}$ long) with a pair of unfolded leaves in Magenta-type vessels containing halfstrength MS solution without sugar or vitamins, with high number of air exchanges $\left(3.9 \mathrm{~h}^{-1}\right.$; estimated according to Kozai et al., 1986). The high number of air exchanges of the vessels was provided by two holes $(10 \mathrm{~mm}$ in diameter) on the lid. To exclude pathogens from entering the vessel, the holes on the lids were covered with gas-permeable membrane filters (Milliseal, pore diameter, $0.5 \mu \mathrm{m}$; Millipore, Japan). Under photoautotrophic conditions, Florialite (vermiculate and cellulose fiber mixture; Nishinbo Industries Inc., Tokyo, Japan) was used as supporting material (15 g per vessel), and each vessel contained $50 \mathrm{ml}$ of the medium. Photosynthetic photon flux (PPF) was $150 \mu \mathrm{mol} \mathrm{m} \mathrm{m}^{-2} \mathrm{~s}^{-1}$ measured on an empty shelf surface, and $\mathrm{CO}_{2}$ concentration was $1,000 \pm 50 \mu \mathrm{mol} \mathrm{mol}^{-1}$. All other conditions were similar to those described above for plantlets grown under photomixotrophic conditions.

\section{Acclimatization and treatments}

At the end of in vitro culture (day 21), $\mathrm{Pm}$ and $\mathrm{Pa}$ were transferred into pots $(6 \mathrm{~cm}$ in diameter) containing commercial substrate (Napura, Yanmar Co., Japan) and cultured ex vitro in a growth chamber (Koito FR 9108A, Koito Industries, LTD., Tokyo, Japan) equipped with controllers for environmental factors such as temperature, $\mathrm{CO}_{2}$ concentration, photoperiod, relative humidity, PPF, etc. The ex vitro environmental conditions were $25 \pm 2{ }^{\circ} \mathrm{C}$ air temperature, $16 \mathrm{~h}$ photoperiod, 300 $\mu \mathrm{mol} \mathrm{m} \mathrm{s}^{-1}$ PPF, $1.25 \mathrm{~m} \mathrm{~s}^{-1}$ air current speed, and $1000 \pm 50 \mu \mathrm{mol} \mathrm{mol}^{-1} \mathrm{CO}_{2}$ concentration. The $\mathrm{Pm}$ and $\mathrm{Pa}$ were randomly divided into four groups and placed into growth chambers for acclimatization by gradually reducing the relative humidity from 90 to $65 \%$, within two (T2), four (T4) or seven (T7) days, or immediately (T0) at 65\%. Relative humidity was reduced once a day, and it was similar throughout the day and night periods. Reduction rates per day were $12.5 \%$ for $\mathrm{T} 2$, $6.3 \%$ for $\mathrm{T} 4$ and $2.6 \%$ for $\mathrm{T} 7$, calculated by dividing the difference between the initial relative humidity $(90 \%)$ and final relative humidity $(65 \%)$ by number of acclimatization days (e.g. rate for $\left.\mathrm{T} 2=(90 \%-65 \%) / 2=12.5 \% \mathrm{~d}^{-1}\right)$. Half-strength Hyponex (Hyponex Co., Ltd., Japan, 6-10-5 NPK) nutrient solution ( $\mathrm{pH} 5.5$ ) was used to irrigate the plants every other day. On day 35 (14 days after transferring), chlorophyll concentration, fresh mass, dry mass, and survival percentage of plants were determined. There were four periods of acclimatization (T0, T2, T4 and T7) for both $\mathrm{Pm}$ and $\mathrm{Pa}$ consisting in eight treatments. Each treatment consisted of six replications, each with two plants. Therefore, there were twelve plants per treatment. The experiment was conducted 
twice.

Statistical analysis

Statistical significance was determined by analyses of variance (ANOVA) using SigmaStat ${ }^{\mathrm{TM}}$ (V 2.03, SPSS Inc.) for Windows ${ }^{k}$. Differences between means were assessed with the NewmanKeulls means separation test using SigmaStat.

\section{RESULTS}

At the end of in vitro culture (day 21), St. John's wort plantlets grown under photoautotrophic conditions $(\mathrm{Pa})$ showed greater growth than those grown under photomixotrophic conditions $(\mathrm{Pm})$ (Fig. 1A and B). On day 21, fresh and dry mass were $280 \pm 26 \mathrm{mg}$ and $27 \pm 2 \mathrm{mg}$ for Pa and $34 \pm$ $4 \mathrm{mg}$ and $7 \pm 1 \mathrm{mg}$ for Pm, respectively. On day 35 (21 days in vitro and 14 days after transferring to ex vitro environments under artificial light), all plants survived $(100 \%)$ in all treatments. The Pa showed, on average, $3.7 \times$ more fresh mass (Fig. 2A) and $4.0 \times$ more dry mass (Fig. 2B) than the Pm, regardless of the period of acclimatization. Similarly, root and shoot fresh and dry mass, were approximately $4.0 \times$ greater for the $\mathrm{Pa}$ than for the Pm, regardless the period of acclimatization.

The duration of the ex vitro acclimatization stage had a significant influence on the growth of the Pa, but not on the growth of the Pm (Fig. 2). On day 35, among the Pa treatments, total fresh and dry mass (Fig. $2 \mathrm{~A}$ and $2 \mathrm{~B}$, respectively) were greatest in the $\mathrm{Pa}$ acclimatized ex vitro by decreasing the relative humidity from $90 \%$ to $65 \%$ within two days (Pa-T2: $\mathrm{FM}=2.7 \mathrm{~g}$ and $\mathrm{DM}=0.33 \mathrm{~g})$ or within four days $(\mathrm{Pa}-\mathrm{T} 4: \mathrm{FM}=2.2 \mathrm{~g}$ and $\mathrm{DM}=0.32 \mathrm{~g})$. Intermediate values of fresh and dry mass were observed for treatments of Pa-T7 (FM=1.9 g and DM=0.21 g) and Pa-T0 $(F M=1.9 \mathrm{~g}$ and $\mathrm{DM}=0.22 \mathrm{~g})$. Pm treatments showed low fresh and dry mass values $(\mathrm{FM}=0.6 \mathrm{~g}$ and $\mathrm{DM}=0.07 \mathrm{~g}$, on average), regardless the period of acclimatization (Fig. 2). Root growth was not significantly different either among the Pm or Pa treatments, and the difference was mainly due to the growth of shoots (leaves and stems).

On day 35, chlorophyll concentrations were highest in the $\mathrm{Pa}$ acclimatized ex vitro within two days (Pa-T2: $640 \mu \mathrm{g} \mathrm{g}^{-1}$ fresh mass) or within seven days (Pa-T7: $571 \mu \mathrm{g} \mathrm{g}^{-1}$ fresh mass) days, or in the $\mathrm{Pa}$ transferred directly to $65 \%$ relative humidity ( $\mathrm{Pa}-\mathrm{T} 0: 586 \mu \mathrm{g} \mathrm{g}^{-1}$ fresh mass) (Fig. 3). Intermediate values of chlorophyll concentrations were found in the treatments of Pa-T4 $(524 \mu \mathrm{g}$ $\mathrm{g}^{-1}$ fresh mass), Pm-T4 (437 $\mu \mathrm{g} \mathrm{g}^{-1}$ fresh mass) and Pm-T7 (468 $\mu \mathrm{g} \mathrm{g}^{-1}$ fresh mass), and the lowest values were in the treatments of Pm-T2 (344 $\mu \mathrm{g} \mathrm{g}^{-1}$ fresh mass) and Pm-T0 (344 $\mu \mathrm{g} \mathrm{g}^{1}$ fresh mass).

\section{DISCUSSION}

Growth of St. John's wort plants and production of their bioactive compounds were shown to be promoted by growth under controlled environments with artificial light (Zobayed et al., 2005).

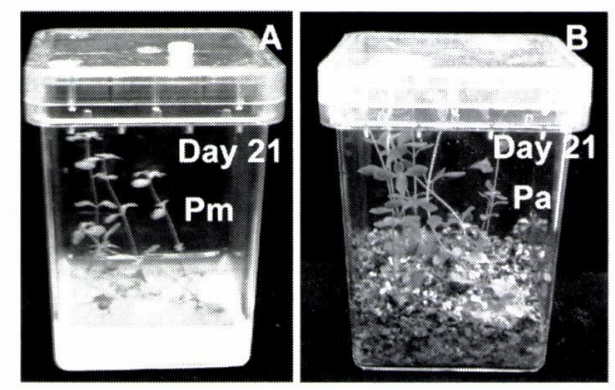

Fig. 1 Plantlets grown photomixotrophically (Pm) and photoautotrophically (Pa) in vitro for 21 days (A and B, respectively). 


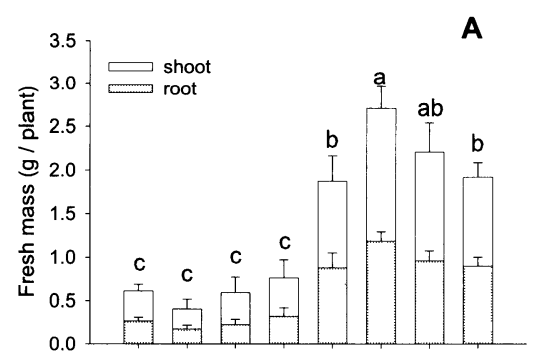

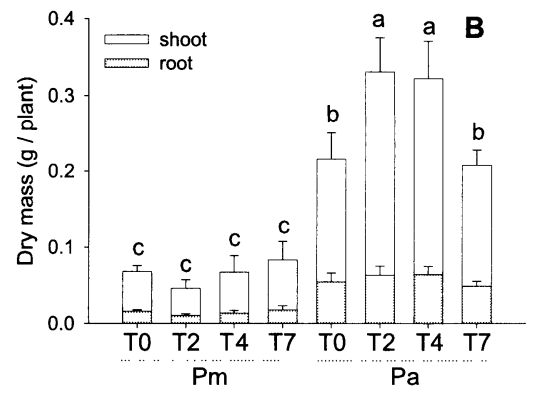

Fig. 2 Effects of photomixotrophic (Pm) and photoautotrophic $(\mathrm{Pa})$ in vitro conditions, and periods of acclimatization $(0,2,4$ and 7 days) on root, shoot (leaves and stems) and total fresh (A) and dry mass (B) of St. John's wort plants grown for 14 days under controlled environments with artificial light. Significance of differences was based on total fresh and dry mass. The separation of means was assessed by the Newman-Keuls test, $P$ $<0.05$.

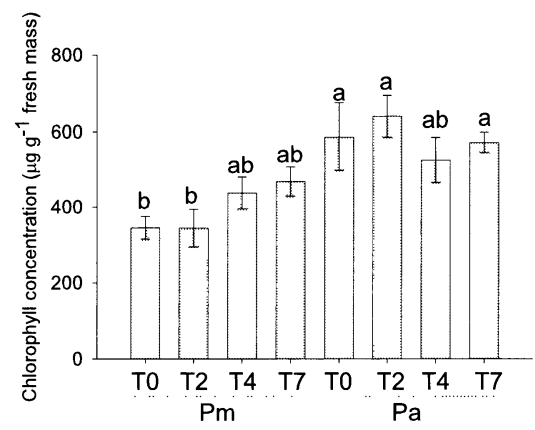

Fig. 3 Effects of photomixotrophic (Pm) and photoautotrophic $(\mathrm{Pa})$ in vitro conditions, and periods of acclimatization $(0,2,4$ and 7 days) on chlorophyll concentrations of St. John's wort plants grown for 14 days under controlled environments with artificial light. Chlorophyll concentration was measured in the second or third leaf (unfolded and fully expanded) from the apex. The separation of means was assessed by the Newman-Keuls test, $P<0.05$.

The improvements were mainly attributed to elimination of changeable environments that occurs in greenhouses under natural light or in the field, maintaining the environmental conditions in an optimum range throughout the growing period, and reduction of contamination by insect, pathogens and pollutants. Moreover, high survival percentages and reduction or elimination of the period of ex vitro acclimatization stage is expected without retardation of the growth of plants when plants are transferred under stable environments (Kozai et al., 2005). In addition, the cost of ex vitro acclimatization under artificial light is not high compared with the traditional method using natural light in greenhouses (Kozai et al., 2005). In the current study, we were able to successfully acclimatize both $\mathrm{Pm}$ and $\mathrm{Pa}$ under controlled environments with artificial light. Moreover, as a highlight of the results, photoautotrophically in vitro grown plants were rapidly acclimatized to an ex vitro environment by decreasing the relative humidity from 90 to $65 \%$ within two days showing accelerated growth when compared to other Pa treatment plants.

Plants from conventional (photomixotrophic) in vitro systems often have malfunctioning stomata (Zobayed et al., 1999), poor wax development (Afreen et al., 2000), poor root development (Afreen et al., 2000), low chlorophyll concentration (Couceiro et al., 2006a), and low net photosynthetic rate (Couceiro et al., 2006a) resulting in poor growth after the transfer to ex vitro environments. These abnormal morphological and physiological characteristics are mainly due to the photomixotrophic in vitro environment, which is entirely different from the ex vitro environment 


\section{A. COUCEIRO ET AL.}

(Kozai et al., 2005). In order to overcome these problems and to avoid retardation of growth and loss of plants during the ex vitro acclimatization, the use of a photoautotrophic system for in vitro plant production can be considered as a suitable solution. The concept of photoautotrophic in vitro propagation is derived from recent research that revealed relatively high photosynthetic ability of chlorophyllous cultures in vitro in sugar-free medium, and has also revealed that the growth of such cultures and percent survival of plantlets ex vitro can be considerably improved (Fujiwara and Kozai, 1995). In the current study, the highest growth rate among the Pa treatments was $172 \mathrm{mg}$ $\mathrm{FM} \mathrm{d}^{-1}$ and $52 \mathrm{mg} \mathrm{DM} \mathrm{d}^{-1}$ in Pa-T2, meanwhile the highest growth rate among the Pm treatments was $22 \mathrm{mg} \mathrm{FM} \mathrm{d}^{-1}$ and $6 \mathrm{mg} \mathrm{DM} \mathrm{d}^{-1}$ in Pm-T7, throughout the ex vitro period (from day 21 to day 35 ). The above results suggest that the photoautotrophic in vitro conditions positively affected the growth of the plants after transferred to ex vitro under controlled artificial light. Our results are in close agreement with the findings of Kozai et al. (2005). This study reported that due to the responses to different physical, and chemical elicitors, enhancement of the growth and quality of photoautotrophic plants after transferring to ex vitro environments can be achieved when the plants are cultured in an optimum range of in vitro conditions.

St. John's wort in vitro-grown plantlets have been acclimatized under controlled environments with artificial light by the same methodology used under greenhouse conditions with natural light. In greenhouses under natural light, plantlets have been acclimatized by gradually reducing the humidity from over $90 \%$ (typical in vitro conditions) to ambient humidity in seven to 14 days. Murch et al. (2000) transferred St. John's wort in vitro-grown plantlets into pot soil, and acclimatized them on a mist-bed misting system for two weeks. Pretto and Santarem (2000) transferred St. John's plantlets into a moistened mixture of soil and perlite, gradually exposed them to ambient humidity over a period of 10 days in a growth chamber, and then transferred the acclimatized plants to a greenhouse under partial shade. Zobayed et al. (2004) acclimatized the in vitro plantlets in a greenhouse under natural light by covering them with a transparent plastic sheet and gradually exposing them to the ex vitro environment within over a period of seven days. As mentioned above, one of the advantages of growing plants under controlled environments with artificial light is the possibility of a rapid ex vitro acclimatization with high percentage of surviving plants and rapid growth after the transfer (Zobayed and Saxena, 2004; Kozai et al., 2005). The Pa were successfully transferred and acclimatized ex vitro (100\% survival) under a controlled environment with artificial light in only $48 \mathrm{~h}$ (two days), and showed the greatest growth among the Pa treatments. The Pa whose ex vitro acclimatization periods were either zero (Pa-T0) or seven days (Pa-T7) showed approximately $20 \%$ lower fresh and dry mass than those acclimatized within two days (Pa-T2) (Fig. 2). The possible reason for the reduced fresh and dry mass of plantlets grown photoautotrophically in vitro and acclimatized for longer periods is that high relative humidity condition is related to cause low transpiration rate and difficulty in nutrient uptake (Kozai, 1991). On the other hand, the $\mathrm{Pm}$ that were acclimatized under artificial light for zero or two days (Pm-T0 or Pm-T2) showed the lowest chlorophyll contents among all treatments, on day 35, while the Pm that were acclimatized for periods longer than four days (Pm-T4 and Pm-T7) had high chlorophyll concentrations as the $\mathrm{Pa}$ (Fig. 3). Chlorophyll concentration was found to be related to the photochemical efficiency of photosystem II (Bolhar-Nordenkampf and Oquist, 1993; Kirdmanee et al., 1995), therefore plants grown photomixotrophically in vitro and acclimatized for periods longer than four days might have superior physiological characteristics than those acclimatized for shorter periods ( $\mathrm{Pm}-\mathrm{T} 0$ and $\mathrm{Pm}$ T2). The results indicate that plants propagated photomixotrophically in vitro must be acclimatized for periods longer than four days to obtain higher photosynthetic ability under artificial light. Our results are in close agreement with the findings of Kozai et al. (2005), which showed that the control of the ex vitro environments under artificial light for plant production can shorten the period of ex vitro acclimatization, increase survival to nearly $100 \%$, and consequently reduce labor costs.

In conclusion, we showed that St. John's wort in vitro-grown plants could be successfully 
acclimatized ex vitro under controlled environments with artificial light. Moreover, the photoautotrophic plants had a shorter ex vitro acclimatization duration than the photomixotrophic plants. The combination of a photoautotrophic in vitro propagation system, and a controlled environment with artificial light system is well suited for large scale production of St. John's wort. This combination can produce standardized, safe and high quality plant materials in a short period with low labor costs.

We thank Dr. Kriengkrai Mosaleeyanon, National Center for Genetic Engineering and BiotechnologyThailand, for his kind help with this manuscript.

\section{REFERENCES}

Afreen, F., Zobayed, S. M. A., Kubota, C., Kozai, T. 2000. Physiology of in vitro plantlets grown photoautotrophically. In "Transplant Production in the 21 st Century" (ed. by Kubota, C., Chun, C.), Kluwer Academic Publishers, Dordrecht, p 238-245.

Bolhar-Nordenkampf, H. R., Oquist, G. 1993. Chlorophyll fluorescence as a tool in the photosynthetic research. In "Photosynthesis and Production in a Changing Environment: A Field and Laboratory Manual" (ed. by Hall, D.O., Scurlock, J.M.O., Bolhar-Nordenkampf, H.R., Leegood, R.C., Long, S.P.), Chapman \& Hall, London, p 193-206.

Consumer Safety Symposium on Dietary Supplements and Herbs. 1998. New Good Housekeeping Institute study finds drastic discrepancy in potencies of popular herbal supplement. News release. Good Housekeeping Institute. New York.

Couceiro, M. A., Afreen, F., Zobayed, S. M. A., Kozai, T. 2006a. Enhanced growth and quality of St. John's wort (Hypericum perforatum L.) under photoautotrophic in vitro conditions. In Vitro Cell. Dev. Biol.-Plant 42: in press.

Couceiro, M. A., Afreen, F., Zobayed, S. M. A., Kozai, T. 2006b. Variation of major bioactive compounds of St. John's wort: effects of harvesting time, temperature and germplasm. Plant Sci. 170: 128-134.

Deltito, J., Beyer, D. 1998. The scientific, quasi-scientific and popular literature of the use of St. John's wort in the treatment of depression. J. Affect. Disorders 51: 245-251.

Fujiwara, K., Kozai, T. 1995. Physical microenvironment and its effects. In "Automation and Environmental Control in Plant Tissue Culture" (ed. by Aitken-Christie, J., Kozai, T., Smith, M.L.), Kluwer Academic Publishers, Dordrecht, p 319-369.

Grunwald, J. 1999. The world market for Hypericum products. Nutraceuticals World May/June: 22-25.

Kamboj, V. P. 2000. Herbal medicine. Current Sci. 78: 35-39.

Kirdmanee, C., Kitaya, Y., Kozai, T. 1995. Rapid acclimatization of Eucalyptus plantlets by controlling photon flux density and relative humidity. Environ. Control Biol. 33: 123-132.

Kozai, T., Fujiwara, K., Watanabe, I. 1986. Fundamental studies of environments in plant tissue culture vessels. (2) Effects of stoppers and vessels on gas exchange rates between inside and outside of vessels closed with stoppers. (Japanese text with English abstract) J. Agric. Meteorol. 42: 119-127.

Kozai, T. 1991. Acclimatization of micropropagated plants. In "Biotechnology in Agriculture and Forestry 17: High-tech and Micropropagation I” (ed. by Bajaj, Y.P.S.), Springer-Verlag, New York, p 127-141.

Kozai, T., Ohyama, K., Afreen, F., Zobayed, S., Kubota, C., Hoshi, T., Chun, C. 1999. Transplant production in closed systems with artificial lighting solving global issues on environment conservation, food, resources and energy. Proc. ACESYS III Conf., 23 July, New Brunswick, CCEA, Rutgers Univ., p 31-45.

Kozai, T., Afreen, F., Zobayed, S. M. A. 2005. Photoautotrophic (sugar-free medium) Micropropagation as a New Propagation and Transplant Production System. Springer, Dordrecht, pp 315.

Miller, A. L. 1998. St. John's wort (Hypericum perforatum): clinical effects on depression and other conditions. Altern. Med. Rev. 3: 18-26.

Mosaleeyanon, K., Zobayed, S. M. A., Afreen, F., Kozai, T. 2005. Relationships between net photosynthetic rate and secondary metabolite contents in St. John's wort. Plant Sci. 169: 523-531.

Murashige, T., Skoog F. 1962. A revised medium for rapid growth and bioassays with tobacco tissue cultures. Physiol. Plant 15: 473-497.

Murch, S. J., Choffe, K. L., Victor, J. M. R., Slimmon, T. Y., Krishna Raj, S., Saxena, P. K. 2000. Thidiazuron- 


\section{A. COUCEIRO ET AL.}

induced plant regeneration from hypocotyls cultures of St. John's wort plants (Hypericum perforatum Cv. 'Anthos'). Plant Cell Rep. 19: 576-581.

Orth, H. C., Rentel, C., Schmidt, P. C. 1999. Isolation, purity analysis and stability of hyperforin as a standart material from Hypericum perforatum L. J. Pharm. Pharmacol. 51: 193-200.

Preece, J. E., Sutter, E. G. 1991. Acclimatization of micropropagated plants to the greenhouse and field, In "Micropropagation. Technology and Application" (ed. by Debergh, R.H., Zimmerman, R.H.), Kluwer, Dordrecht, p 71-93.

Pretto, F. R., Santarem E. R. 2000. Callus formation and plant regeneration from Hypericum perforatum) leaves. Plant Cell Tissue Organ Cult. 62: 107-113.

Schempp, C. M., Krikin V., Simon-Haarhaus, G., Kersten, A., Kiss, J., Termeer, C. C., Gilb, B., Kaufmann, T., Borner, C., Sleeman, J. P., Simon, J. C. 2002. Inhibition of tumor cell growth by hyperorin, a novel anticancer drug from St. John's wort that acts by induction of apoptosis. Oncogene 21: 1242-1250.

Zobayed, S. M. A., Afreen-Zobayed, F., Kubota, C., Kozai, T. 1999. Stomatal characteristics and leaf anatomy of potato plantlets cultured in vitro under photoautotrophic and photomixotrophic conditions. In Vitro Cell, Dev. Biol.-Plant 35: 183-188.

Zobayed, S. M. A., Murch, S. J., Rupasinghe, H. P. V., Saxena, P. K. 2004. In vitro production and chemical characterization of St. John's wort (Hypericum perforatum L. cv 'New Stem'). Plant Sci. 166: 333-340.

Zobayed, S. M. A., Saxena, P. K. 2004. Production of St. John's wort plants under controlled environment for maximizing biomass and secondary metabolites. In Vitro Cell. Dev. Biol.-Plant 40: 108-114.

Zobayed, S. M. A., Afreen, F., Kozai, T. 2005. Necessity and production of medicinal plants under controlled environments. Environ. Control Biol. 43: 243-252. 